\title{
About Dr. Darwish
}

$\mathrm{D}$ r. Azza Darwish had a very busy pediatric practice. I first contacted her office when our youngest son, Aaron, was three weeks old. We had just received the unexpected news that our baby had Down syndrome.

The receptionist immediately booked us into a noon spot the next day. When my husband Mike and I arrived at the clinic, it was actually closed for lunch. I was grateful to just sit in the quiet waiting room and not be surrounded by seemingly "normal" babies. That would have been difficult in the fragile early days of Aaron's diagnosis. I was living under a thick veil of grief where everything was very dark. I did not want happy, gurgling babies obstructing my view.

We were escorted to Dr. Darwish's treatment room. Mike carried Aaron, who was asleep in his car seat. The room was filled with photographs of Dr. Darwish's patients - typical-looking kids, kids with facial differences, kids in wheelchairs and, yes, I recognized the heart-shaped faces of children with Down syndrome too. The display was a beautiful celebration of the diversity in her practice.

We perched anxiously in our chairs, not talking. I picked nervously at my fingers as Mike stared at the ceiling.

Soon after, Dr. Darwish knocked on the door, came in and introduced herself. The very first thing she did was scoop my slumbering son out of his car seat and hold him in her arms. Today, 10 years later, I can still close my eyes and recall this well-dressed physician cuddling Aaron. It is a powerful image.

"You have a beautiful baby boy," she said, and a lovely smile spread across her face.

In the first weeks since Aaron's diagnosis, we had visited many health professionals. Not one of them had held Aaron. Not one of them had com-

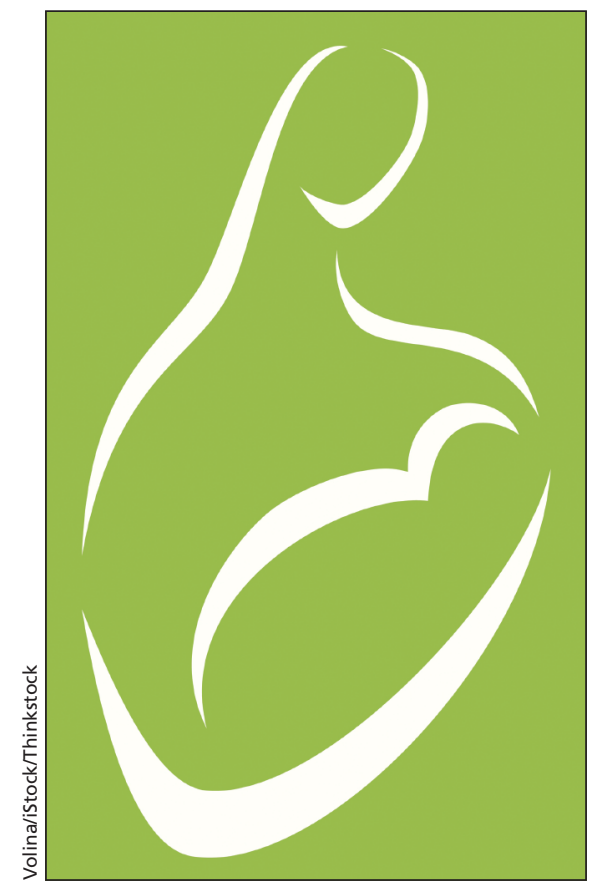

mented on how beautiful he was (and he was indeed beautiful - wee, soft, a bit floppy with a mess of dark, punkrock hair). Up to that point, Dr. Darwish was the only clinician to see Aaron as a baby first. She didn't immediately zero in on what was "wrong" with him. She first saw, and expressed, what was right.

She continued chatting with us: "It must have been quite a shock for you to receive the Down syndrome diagnosis." This opened the door for us to talk about how we felt about Aaron's diagnosis. Again, not one other clinician had asked us how we were emotionally. They had all talked about risks, statistics and data. Nobody had focused on what was invisible to the eye.

Our appointment was close to an hour long. I knew that was almost unheard of in the world of medicine (and even less likely for a physician to spend her entire lunch hour with a family she did not even know). Dr. Darwish asked us if we wanted to see some of Aaron's physical markers. We did. She gently pointed them out. She carefully opened Aaron's hands, as if to read his palm. She softly showed us his lowerset ears and the gap between his toes. She murmured gently to him as she carried out her examination. He was not a laboratory specimen to her. She treated him with such dignity, as if he were her own child. A decade later, my eyes still well up, recalling this kindness.

Dr. Darwish patiently explained all of the services available to us, and suggested we get in touch with our local support group so we could meet other families who had children with Down syndrome. She said her office would look after all the tests and referrals we required - echocardiogram, electrocardiogram, audiology and ophthalmology. She made an overwhelming and difficult experience more manageable and, ultimately, more humane.

Azza Darwish passed away from cancer eight years ago. She was 52 years old. She is sorely missed in our community because of her skill as a clinician, as she had many children with Down syndrome in her practice. But she is mostly missed because of her compassion as a human being. She was a beloved pediatrician.

I cannot overstate the importance of giving patients and families the gifts of compassion and hope. After that appointment with Dr. Darwish, my thick veil of grief began to lift, albeit ever so slowly. From beneath that veil, I caught my first real glimpse of my little boy. He continues to shine his light brightly on us today. Thank you, Azza, for this gift.

\section{Sue Robins BA}

Writer

Edmonton, Alta.

This is a true story. Dr. Darwish's family has given consent for this story to be told.

CMAJ 2014. DOI:10.1503/cmaj.140242 